\title{
CONHECER PARA CONSERVAR: RECONHECIMENTO DA FAUNA NATIVA DO CERRADO POR ALUNOS DO DISTRITO FEDERAL
}

Raphael Igor Dias ${ }^{1}$

Brenda Elias dos Reis²

Resumo: O conhecimento sobre biodiversidade local por parte da população é um componente importante para o sucesso de políticas de conservação. Nesse sentido, o objetivo deste trabalho foi investigar o conhecimento de alunos do ensino fundamental em relação à fauna do Cerrado e sobre conceitos relacionados à conservação das espécies através da aplicação de questionários. Percebeu-se que os participantes identificaram mais espécies exóticas do que as nativas. Apesar de não reconhecerem com facilidade as espécies nativas, a maioria dos alunos demonstrou conhecer os conceitos de espécie ameaçada e extinta. O desconhecimento dos alunos sobre as espécies nativas pode estar relacionado a uma maior exposição, tanto na mídia quanto nos próprios livros didáticos de informações sobre espécies exóticas.

Palavras-chave: Conservação; Diversidade Biológica; Educação Ambiental; Ensino de Ciências; Espécie Ameaçada. 


\section{Introdução}

O bioma Cerrado está distribuído em uma área continua e extensa que ocupa os estados de Goiás, Bahia, Minas Gerais, Mato Grosso, Mato Grosso do Sul e Tocantins, além do Distrito Federal e alguns enclaves e penínsulas que se espalham por outros estados (MMA, 2016). O termo Cerrado é usualmente empregado para caracterizar um conjunto de fitofisionomias (campo sujo, campo limpo, campo rupestre, mata ciliar, matas de galeria, mata mesofítica, cerradão, cerrado "stricto sensu", capoeira) que ocorrem no Brasil Central. No Cerrado estão as nascentes das três maiores bacias hidrográficas da América do Sul: a Amazônica, a Tocantins e a do São Francisco, o que favorece a sua biodiversidade (FELFILI et al., 2005; RIBEIRO et al., 2008).

Cerca de $23 \%$ do território brasileiro era originalmente ocupado pelo Cerrado. No entanto, o Cerrado já não apresenta mais a mesma cobertura original e a cada ano as atividades antrópicas alteram a extensão do bioma, sem que se tenha pleno conhecimento sobre os efeitos nas várias espécies vegetais e animais que o habitam (PRIMACK; RODRIGUES, 2001; KLINK; MOREIRA, 2002). Se a taxa de desmatamento do Cerrado se mantiver nos níveis atuais, estudos apontam que o bioma será extinto até o ano de 2030 (MACHADO et al., 2004).

O Cerrado possui uma grande diversidade de vertebrados, sendo registradas no bioma aproximadamente 199 espécies de mamíferos, 837 espécies de aves, 180 espécies de répteis e 150 espécies de anfíbios (COLLI et al., 2002; MACEDO, 2002; MARINHO-FILHO, 2002). O número de espécies vegetais também é elevado, existindo algo em torno de 10 mil espécies, sendo 4.400 endêmicas do Cerrado (RIBEIRO et al., 2008). Apesar disso, estudos anteriores demonstraram alta prevalência de opiniões negativas em relação à estrutura e diversidade do Cerrado, sugerindo que o bioma apresenta baixa diversidade e que é menos exuberante do que biomas florestais, demonstrando desconhecimento e desinteresse da população sobre o bioma (BIZERRIL, 2004).

Devido ao impacto humano no Cerrado, que abriga em torno de $33 \%$ da diversidade biológica do Brasil e cerca de $5 \%$ da fauna mundial, a diversidade faunística do bioma está sendo afetada negativamente em uma velocidade superior à capacidade de promover o conhecimento necessário para sua conservação (DIAS, 1992a; MYERS et al., 2000; AGUIAR et al., 2004; KLINK; MACHADO, 2005).

Alterações no bioma ameaçam as espécies nativas por meio da fragmentação, da redução de áreas naturais e da diminuição da qualidade do hábitat, reduzindo e isolando as populações (ALHO, 1995). Esses efeitos podem ser observados, por exemplo, no tiê-bicudo (Conothraupis mesoleuca) e no pato-mergulhão (Mergus octosetaceus), espécies criticamente ameaçadas de extinção devido ao desmatamento, a expansão agrícola, a construção de hidrelétricas e o crescimento populacional desordenado (BRAZ et al., 2003; BARBOSA; ALMEIDA, 2010; CANDIA-GALLARDO et al., 2010). Esse processo

revista brasileira educação ambiental 
de transformação das condições ambientais pode resultar na extinção de espécies da natureza, ou seja, quando o último indivíduo da espécie é eliminado do ambiente natural (PRIMACK; RODRIGUES, 2001). Exemplos desse processo foram observados para as espécies Phrynomedusa fimbriata, espécie registrada no estado de São Paulo em 1923 e sem registros adicionais por mais de 80 anos e o Mitu mitu, espécie conhecida como Mutum-doNordeste, oficialmente extinto da natureza desde 2001 (CRUZ; PIMENTA, 2004).

Para a prática da educação ambiental é necessário contextualizar conhecimentos teóricos sobre fatores socioambientais e econômicos. Dessa forma, a educação ambiental surge como uma ferramenta para proporcionar a transformação da percepção da sociedade, possibilitando uma base sólida de conhecimento para a formação de cidadãos críticos e éticos nas suas relações com o meio ambiente, contribuindo na busca pela sustentabilidade (DIAS, 1992b; REIGADA; REIS, 2004; COIMBRA, 2006).

Toda sociedade carrega conceitos estabelecidos sobre o que é natureza e qual é a sua composição. Esses conceitos são construídos no dia a dia, através da comunicação, da educação formal e das relações sociais, havendo muitas vezes uma grande abrangência e diferenciação em relação aos conceitos ecológicos teóricos (GONÇALVES, 2002). Ações que acontecem regularmente e progressivamente revelam-se mais eficientes quando o objetivo não é apenas decorar conceitos, mas sim, sensibilizar determinados públicos quanto à importância de proteger e conservar o meio ambiente. Com essa sensibilização, os atores envolvidos são estimulados a buscar pelo saber e transmiti-lo através do seu conhecimento e não por respostas prontas. Dessa forma, o ensino pode caminhar para uma direção que promova a criação de uma nova teoria e visão pessoal (SAUVÉ, 1996; JACOBI, 2005).

O ensino fundamental é uma das etapas mais relevantes na formação do aluno, pois é onde ocorre a edificação de ideias e percepção da realidade e do ambiente que o cerca (MACHADO, 1999; CUTTER-MACKENZIE; SMITH, 2003; CAPRA et al., 2008). Os livros didáticos adotados pela rede pública são normalmente caracterizados pela pouca informação sobre a fauna nativa (BIZERRIL, 2003; COSTA et al., 2010; BEZERRA; SUESS, 2013). Por outro lado, é recorrente o uso de imagens que apresentam paisagens e fauna exóticas. A maioria dos alunos utiliza o livro didático como uma das principais fontes de acesso a informação. Com a desvalorização das espécies nativas nesse material, há um impacto negativo na percepção sobre a necessidade de proteção dessas espécies (PINHEIRO DA SILVA; CAVASSAN, 2003), pois é fundamental conhecer a biodiversidade para que ações de conservação tenham mais sucesso.

Uma pesquisa realizada em uma escola pública de Manaus buscou avaliar, por meio de entrevistas individuais, o entendimento de alunos do ensino fundamental sobre questões ambientais. Os autores perceberam que a maioria dos alunos não conseguiu diferenciar os conceitos de espécies nativas e exóticas e como essas espécies estão inseridas no meio ambiente

Revbea, São Paulo, V. 13, № 4: 260-280, 2018. 
(MORAES; SILVA, 2006). Outra pesquisa realizada com alunos do ensino fundamental de escolas públicas também em Manaus, com objetivo de verificar a relação dos alunos com a floresta amazônica e seus recursos, apontou que os alunos acreditam que a floresta amazônica apresenta animais como elefantes, girafas, leões e tigres. Adicionalmente, metade dos entrevistados não soube distinguir a fauna do nosso continente e de outros continentes, principalmente da África, país de origem da maioria da fauna exótica citada, demonstrando a dificuldade de reconhecer as diferenças entre espécies nativas e exóticas, além de conceitos relacionados à distribuição geográfica das espécies (FREITAS; FERRAZ, 1999). Uma possibilidade para explicar os resultados pode estar no fato de que mesmo que os professores retratem o meio ambiente de uma forma completa, a relação das pessoas com os animais, sejam nativos ou exóticos, praticamente não é tratada em sala de aula (MORAES; SILVA, 2006).

Apesar disso, um estudo que avaliou o conhecimento e interesse dos alunos do ensino básico em questões ambientais, apontou que existe nos alunos uma consciência ecológica, assim como, um interesse na conservação da biodiversidade local. A maioria afirmou que as atividades antrópicas são as principais causas de ameaças aos animais e de destruição de seu habitat (MIRANDA, 2007). Embora a mídia e os livros didáticos retratem mais as espécies da fauna exótica, um maior contato com ambientes naturais pode contribuir para ampliar os conhecimentos sobre a fauna local. Esse efeito foi percebido em um estudo com pais e alunos residentes em zona rural. Nesse estudo, foi solicitado que os pais elaborassem uma lista com animais que conheciam e escolhessem cinco animais para produzir um texto sobre eles. Posteriormente, as mesmas imagens foram mostradas aos educandos para que eles identificassem os animais. Os resultados mostraram que a maioria (84\%) optou por animais nativos, tendo seus conhecimentos, conforme afirmado pelos próprios educandos, fundamentados em suas vivencias diárias (PEDERSOLI, 2008).

Considerando que o conhecimento acerca da fauna do Cerrado pode fornecer elementos para aprimorar o ensino de conceitos ecológicos e repensar a abordagem da educação ambiental no ensino fundamental, o objetivo deste trabalho foi investigar o conhecimento dos alunos sobre conceitos ecológicos relacionados à distribuição e conservação de espécies. Adicionalmente, o estudo pretendeu avaliar a capacidade dos alunos de identificar espécies da fauna nativa do Cerrado, analisar o efeito de espécies carismáticas exóticas no entendimento de conceitos ecológicos, como distribuição de espécies e investigar o conhecimento dos alunos quanto aos conceitos de fauna ameaçada e extinção de espécies. 


\section{Materiais E Métodos}

\section{Público-alvo}

O público-alvo do estudo foi composto por alunos do $8^{\circ}$ ano do ensino fundamental. Essa etapa de ensino foi selecionada pois, conforme descrito no Parâmetros Curriculares Nacionais - PCN (BRASIL, 1998a), os conceitos ecológicos abordados no presente estudo são trabalhados no $3^{\circ}$ ciclo do ensino fundamental. A pesquisa cadastrada sob o número 55017916.9.0000.0023, foi submetida e aprovada pelo Comitê de Ética em Pesquisa do UniCEUB e conforme indicado pelo mesmo, teve dispensada a obtenção do Termo de Consentimento Livre Esclarecido para os participantes de forma individual. Nesse sentido, foi obtida apenas a autorização das escolas selecionadas por meio de um Termo de Anuência liberando a realização da pesquisa na instituição por se tratar de um conteúdo abordado em sala de aula. O estudo foi desenvolvido nas seguintes escolas públicas do Distrito Federal: CEF 104 Norte, CEF 04 de Brasília, CED do Lago Norte, CED do Lago Sul, CEF 04 do Paranoá e CEF 03 de Sobradinho.

\section{Procedimentos gerais}

Para avaliar o conhecimento dos alunos a respeito da fauna do Cerrado, foi aplicado um questionário (Anexo I) composto por vinte e cinco imagens de animais nativos do Cerrado e outras vinte e cinco de animais exóticos, dispostas de maneira aleatória (Tabela 1). Segundo BRASIL (1998b), são consideradas espécies nativas aquelas naturais da região ou que tenham parte do seu ciclo de vida dentro do território nacional. Por outro lado, são consideradas espécies exóticas todas aquelas que não pertencem à fauna original do ambiente em que se encontram. Ao responder os questionários os alunos preencheram informações sobre o nome da escola, a idade e sexo. Todas as imagens utilizadas no questionário apresentaram organismos inteiros em seus habitats naturais. As imagens utilizadas estavam livremente disponíveis na internet nos termos da licença Creative Commons. Abaixo de cada imagem havia um espaço para que o participante escrevesse o nome popular da espécie. Foi explicado para os participantes, que os mesmos deveriam tentar chegar ao menor nível possível de identificação quanto ao nome popular. Por exemplo, a imagem de um beija-flor não deveria ser identificada apenas por pássaro ou passarinho, assim como uma Jiboia não deveria ser identificada apenas como cobra ou serpente. O respondente também foi questionado se o animal da foto era nativo do Cerrado ou exótico e se o mesmo estava ou não ameaçado de extinção. No final do questionário, estavam presentes também duas questões discursivas, sendo elas: "O que significa dizer que uma espécie está ameaçada? "O que significa dizer que uma espécie está extinta? ". O gabarito das questões e os conceitos de nativo, exótico, espécie ameaçada e extinta foram repassados aos alunos no final da aplicação do questionário. 
Tabela 1: Lista de espécies nativas e exóticas utilizadas no questionário aplicado aos alunos do $8^{\circ}$ ano do ensino fundamental. Foi utilizada a classificação criada pela The International

Union for Conservation of Nature (IUCN) para a produção da lista vermelha de espécies ameaçadas (Não avaliada - NE, Menos preocupante - LC, Quase ameaçada - NT, Vulnerável - VU, Em perigo - EN, Criticamente em perigo - CR, Extinta na natureza - EW e Extinta - EX). As espécies ameaçadas estão destacadas em negrito.

\begin{tabular}{|c|c|c|c|}
\hline Distribuição & IUCN & Nome popular & Nome científico \\
\hline \multicolumn{4}{|l|}{ Nativas } \\
\hline & VU & Anta & Tapirus terrestris \\
\hline & LC & Arara-canindé & Ara ararauna \\
\hline & EN & Ariranha & Pteronura brasiliensis \\
\hline & NT & Cachorro-vinagre & Speothos venaticus \\
\hline & LC & Capivara & Hydrochoerus hydrochaeris \\
\hline & NE & Cutia & Dasyprocta aguti \\
\hline & NT & Ema & Rhea americana \\
\hline & LC & Jaguatirica & Leopardus pardalis \\
\hline & NT & Lobo-guará & Chrysocyon brachyurus \\
\hline & LC & Gralha-do-Cerrado & Cyanocorax cristatellus \\
\hline & LC & Macaco-prego & Sapajus libidinosus \\
\hline & LC & Paca & Cuniculus paca \\
\hline & NT & Onça-pintada & Panthera onca \\
\hline & LC & Ouriço-cacheiro & Coendou prehensilis \\
\hline & LC & Quati & Nasua nasua \\
\hline & Vu & Queixada & Tayassu pecari \\
\hline & LC & Raposa-do-campo & Lycalopex vetulus \\
\hline & LC & Saruê & Didelphis albiventris \\
\hline & LC & Sagui & Callithrix penicillata \\
\hline & LC & Seriema & Cariama cristata \\
\hline & VU & Tamanduá-bandeira & Myrmecophaga tridactyla \\
\hline & LC & Tapiti & Sylvilagus brasiliensis \\
\hline & Vu & Tatu-bola & Tolypeutes tricinctus \\
\hline & LC & Teiú & Salvator merianae \\
\hline & DD & Veado-mateiro & Mazama americana \\
\hline
\end{tabular}

Continua... 
...continuação.

\begin{tabular}{|c|c|c|c|}
\hline Distribuição & IUCN & Nome popular & Nome cientifico \\
\hline \multicolumn{4}{|l|}{ Exóticas } \\
\hline & LC & Alce & Alces alces \\
\hline & NT & Antílope & Oryx beisa \\
\hline & LC & Búfalo & Syncerus caffer \\
\hline & LC & Canguru & Macropus giganteus \\
\hline & VU & Coala & Phascolarctos cinereus \\
\hline & EN & Chimpanzé & Pan troglodytes \\
\hline & VU & Elefante & Loxodonta africana \\
\hline & LC & Esquilo & Sciurus carolinensis \\
\hline & VU & Girafa & Giraffa camelopardalis \\
\hline & CR & Gorila & Gorilla gorilla \\
\hline & LC & Hiena & Crocuta crocuta \\
\hline & VU & Hipopótamo & Hippopotamus amphibius \\
\hline & LC & Javali & Phacochoerus africanus \\
\hline & VU & Leão & Panthera leo \\
\hline & LC & Lobo & Canis lupus \\
\hline & LC & Lhama & Lama glama \\
\hline & NT & Monstro-de-gila & Heloderma suspectum \\
\hline & CR & Orangotango & Pongo pygmaeus \\
\hline & NT & Ornitorrinco & Ornithorhynchus anatinus \\
\hline & VU & Panda-gigante & Ailuropoda melanoleuca \\
\hline & LC & Pavão & Pavo cristatus \\
\hline & NT & Rinoceronte & Ceratotherium simum \\
\hline & EN & Tigre & Panthera tigris \\
\hline & LC & Urso-pardo & Ursus arctos \\
\hline & NT & Zebra & Equus quagga \\
\hline
\end{tabular}

Os critérios utilizados na seleção das espécies que ilustram o questionário foram: pertencerem a grupos taxonômicos mais conhecidos, apresentarem ampla distribuição geográfica e serem de porte médio ou grande, de acordo com o grupo taxonômico. As espécies ameaçadas foram identificadas a partir da Red List (Lista Vermelha) das espécies ameaçadas, que é um levantamento feito pela The International Union for Conservation of Nature - IUCN (União Internacional para a Conservação da Natureza e dos Recursos Naturais), que tem como objetivo retratar o estado de conservação de todas as espécies de seres vivos, com exceção dos microrganismos. Decidiu-se adotar apenas a Red List como uma forma de padronizar o critério utilizado para classificar as espécies, tendo em vista que o presente estudo incluiu tanto espécies nativas quanto exóticas. A lista dispõe de nove Revbea, São Paulo, V. 13, № 4: 260-280, 2018. 
categorias de classificação: Extinto (Extinct - EX), Extinto na natureza (Extinct in the Wild - EW), Criticamente em perigo (Critically Endangered - CR), Em perigo (Endangered - EN), Vulnerável (Vulnerable - VU), Quase Ameaçada (Near Threatened - NT), Menos Preocupante (Least Concern - LC), Dados insuficientes (Data Deficiente - DD) e Não avaliado (Not Evaluated - NE), além de informar a constante perda de biodiversidade e assim atentar para a criação de políticas voltadas para a conservação dessas espécies (IUCN, 2016). Nesse estudo foram consideradas ameaçadas as espécies classificadas nas categorias CR, EN e VU.

\section{Análises dos dados}

Para avaliar a chance do aluno acertar o item com base nas características da espécie (nativa vs exótica e ameaçada vs não ameaçada), foi utilizado um modelo linear generalizado misto da família binominal utilizando o pacote Ime4 com a função glmer do programa R 2016 (version 3.3.2; R Core Team, 2016). Foi realizada uma simplificação gradual do modelo através da remoção de variáveis e os modelos resultantes foram comparados com testes de razão de verossimilhança (Likelihood ratio test). A idade, o tipo de distribuição (nativo ou exótico) e o grau de ameaça (ameaçado ou não ameaçado) foram incluídos como variáveis fixas no modelo, já a identidade do aluno entrou como variável aleatória. Dois alunos foram removidos do modelo por não apresentarem informações relativas à idade. Para a produção do modelo, foram consideradas respostas corretas aquelas em que os alunos identificaram corretamente a espécie, além de indicar corretamente o tipo de distribuição e o grau de ameaça. Questões em que os alunos identificaram corretamente a espécie, mas deixaram de responder os outros itens foram consideradas como erradas. As questões discursivas foram avaliadas de forma quantitativa e qualitativa. Inicialmente, foi avaliado se a resposta estava correta ou não e posteriormente as respostas foram agrupadas a partir da similaridade do conteúdo e os padrões foram descritos nas formas de valores percentuais.

\section{Resultados}

O questionário foi aplicado para um total de 144 alunos, dos quais 67 eram do sexo feminino e 77 do sexo masculino. No momento da aplicação do questionário, os participantes tinham em média 13,5 \pm 1,0 anos (mínimo $12 \mathrm{e}$ máximo 18 anos). Das perguntas referentes às 50 espécies abordadas no questionário, os alunos tentaram identificar em média 33,3 \pm 8,1 espécies. Adicionalmente, ainda sobre as mesmas 50 espécies, os alunos responderam, em média, sobre distribuição de 29,9 \pm 9,7 (nativa ou exótica) espécies e classificaram em ameaçada ou não-ameaçada, em média, 28,6 \pm 10,1 espécies.

De forma geral, considerando apenas as questões respondidas, a taxa de acertos por aluno foi, em média, 80,7\% quanto à identificação da espécie, $71,5 \%$ quanto à distribuição e $54,1 \%$ quanto ao nível de ameaça. No entanto,

revista brasileira educação ambiental 
quando considerados somente os alunos que identificaram corretamente a espécie da questão, observou-se que a taxa de acerto para a questão sobre distribuição foi, em média, $35,3 \%$ enquanto que a taxa de acerto para a questão sobre ameaça foi, em média, $24,7 \%$.

Analisando separadamente a taxa de acerto por espécie, percebeu-se que a espécie nativa mais identificada foi a onça-pintada (Panthera onca) com 95,1\% de acertos, seguida do tatu-bola (Tolypeutes tricinctus), da araracanindé (Ara ararauna), da capivara (Hydrochoerus hydrochaeris) e do tamanduá-bandeira (Myrmecophaga tridactyla, Figura 1). Apesar da alta taxa de identificação observada para essas espécies nativas, das cinco espécies mais identificadas pelos alunos, quando consideradas todas as espécies utilizadas nesse estudo, apenas uma era nativa. Por outro lado, das cinco espécies menos identificadas pelos alunos, quatro eram nativas. As espécies nativas menos identificadas pelos alunos foram, o cachorro-vinagre (Speothos venaticus), a seriema (Cariama cristata), o quati (Nasua nasua) e por fim, com apenas 3,5\% de identificação, a gralha-do-Cerrado (Cyanocorax cristatellus).

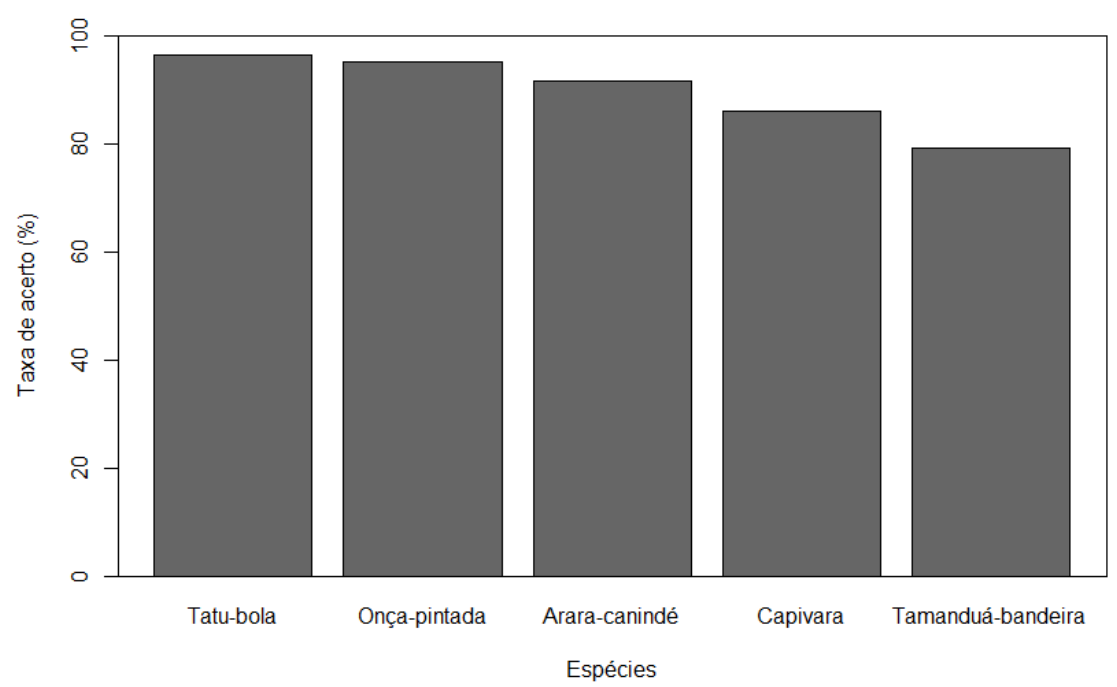

Figura 1: Taxa de acerto das cinco espécies nativas mais identificadas pelos alunos do $8^{\circ}$ ano do ensino fundamental.

A espécie exótica com maior taxa de acerto foi o leão (Panthera leo), com $99,3 \%$ de identificações corretas, seguido do panda-gigante (Ailuropoda melanoleuca), do elefante-africano (Loxodonta africana), do urso-pardo (Ursus arctos) e do tigre (Panthera tigris, Figura 2). As espécies exóticas menos identificadas foram o javali (Phacochoerus africanus), o orangotango (Pongo pygmaeus), o lobo (Canis lupus), o monstro-de-gila (Heloderma suspectum) e o antílope (Oryx beisa), que foi identificado corretamente por $18,7 \%$ dos alunos. 


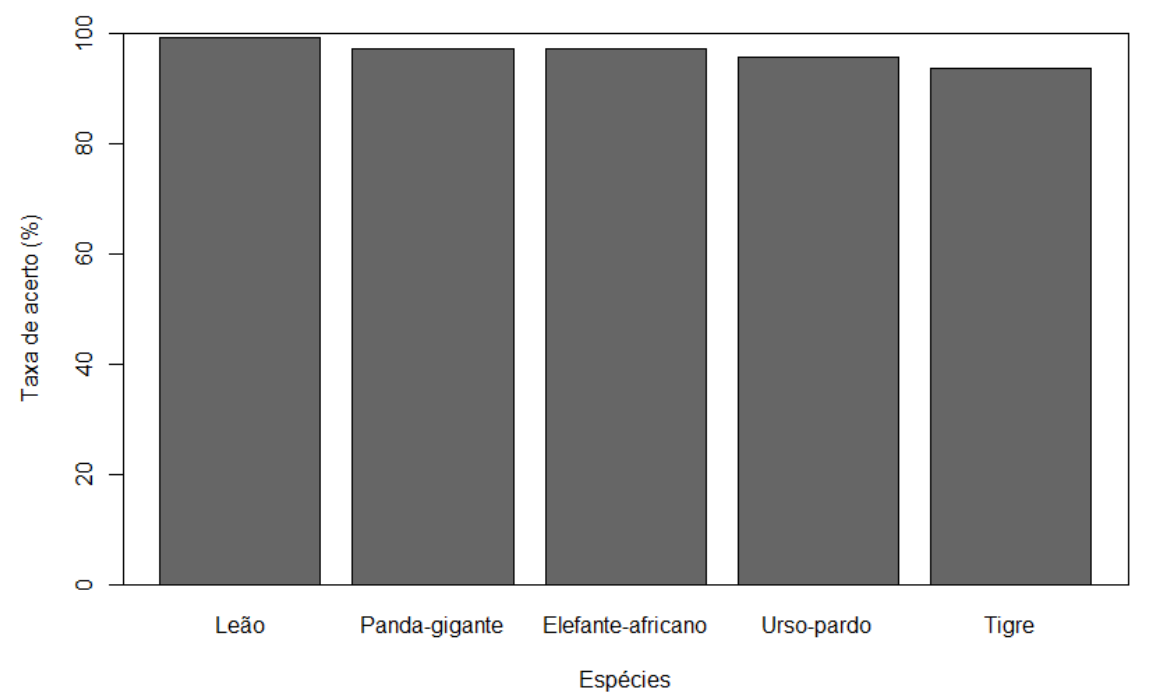

Figura 2: Taxa de acerto das cinco espécies exóticas mais identificadas pelos alunos do 8o ano do ensino fundamental.

Ao avaliar as respostas referentes à identificação das espécies presentes no questionário, foi observado que alguns participantes possivelmente se confundiram devido a similaridades morfológicas das espécies apresentadas com relação a outras espécies. Dentre os equívocos considerados como justificáveis estão a identificação do lobo-guará (Chrysocyon brachyurus) como sendo uma raposa (Lycalopex sp.), da ema (Rhea americana) como um avestruz (Struthio $s p$.) e do búfalo (Syncerus caffer) como um touro (Bos sp.). Por outro lado, algumas respostas divergiram bastante da expectativa. Dentre os equívocos menos justificados destacam-se a identificação do quati (Nasua nasua) como sendo um bicho-preguiça (Bradypus sp.) e do teiú (Salvator merianae) como sendo uma iguana (Iguana $s p$.$) .$

De forma geral, os alunos demostraram ser capazes de identificar boa parte dos animais nativos e exóticos. Apesar disso, algumas espécies características do Cerrado como, por exemplo, a seriema (Cariama cristata) e o lobo-guará (Chrysocyon brachyurus) só foram classificadas como nativas por $14,6 \%$ e $65,3 \%$ dos participantes, respectivamente. Por outro lado, espécies amplamente conhecidas como sendo características de outros biomas, como a girafa (Giraffa camelopardalis) e o elefante (Loxodonta africana), apresentaram, respectivamente $82,6 \%$ e $84,0 \%$ de acertos sobre a sua distribuição. Porém, cabe ressaltar que em média $16,7 \%$ dos alunos indicaram que essas espécies eram pertencentes do bioma Cerrado.

Em relação ao conhecimento dos alunos sobre o nível de ameaça das espécies apresentadas, observou-se que, em média, $75,3 \%$ dos alunos reconheceram corretamente as espécies exóticas ameaçadas de extinção. Por outro lado, apenas $64,7 \%$ dos alunos conseguiram identificar corretamente as espécies nativas ameaçadas de extinção. Das espécies exóticas, o 
orangotango ( $P$. pygmaeus) foi a espécie menos indicada como ameaçada pelos alunos $(40,3 \%)$. Já em relação às espécies nativas, a anta (Tapirus terrestres) foi a espécie ameaçada que os alunos menos indicaram como tal $(36,1 \%)$.

Ao investigarmos como a idade, o tipo de distribuição da espécie e o nível de ameaça influenciou a probabilidade do aluno acertar ou errar a questão, percebeu-se uma tendência não significativa para um efeito da idade (Tabela 2). Embora a interação entre o tipo de distribuição e o nível de ameaça não tenha sido significativa, quando analisadas separadamente, ambas afetaram significativamente a chance do aluno acertar ou errar a questão (Tabela 2). A probabilidade de acerto foi maior para as espécies exóticas (Figura 3) e, surpreendentemente, para as espécies não-ameaçadas (Figura 4).

Tabela 2: Resultado do modelo linear generalizado misto que investigou os efeitos da idade, da distribuição da espécie (nativas - $\mathrm{N}$ ou exótica - E), e se espécie estava ameaçada de extinção (sim - S ou não - N).

\begin{tabular}{lcccc}
\hline Variável & Estimativa & $\mathrm{SE}$ & $\chi^{2}$ & $\mathrm{P}$ \\
\hline Idade & $-0,108$ & 0,062 & 3,46 & 0,062 \\
Distribuição (N) & $-0,269$ & 0,076 & 12,84 & $<0,001$ \\
Ameaçada (S) & $-0,262$ & 0,074 & 12,64 & $<0,001$ \\
Distribuição (N): Ameaçada (S) & 0,244 & 0,159 & 2,31 & 0,128 \\
\hline
\end{tabular}

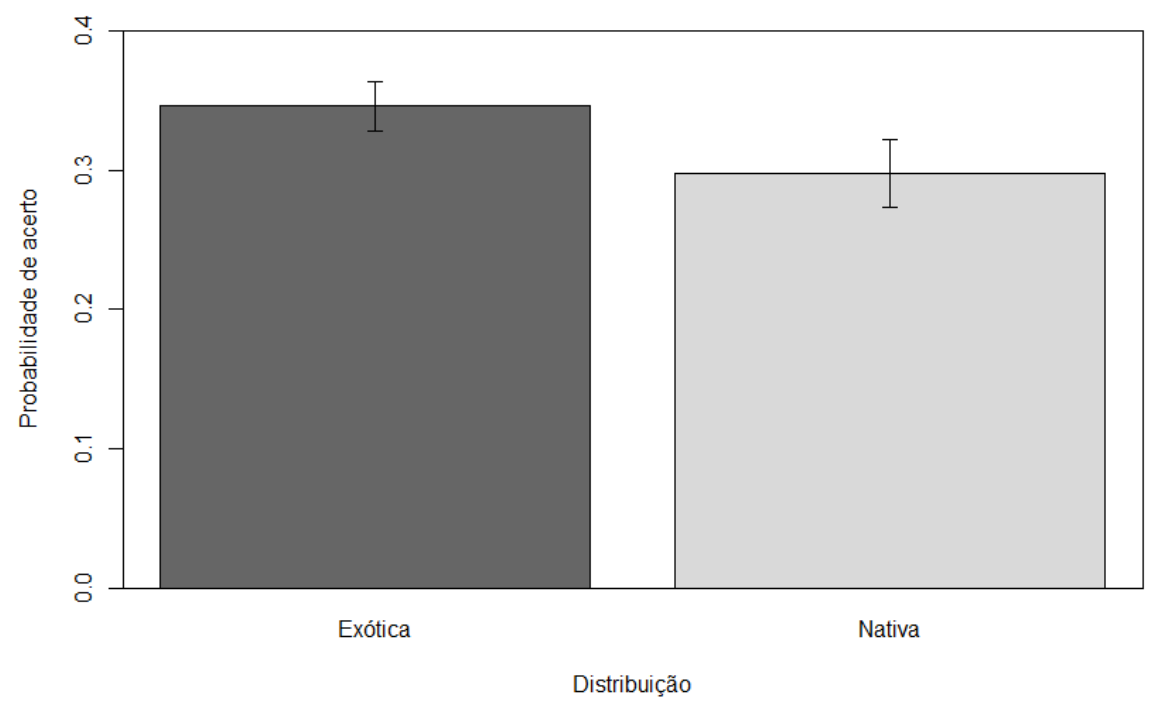

Figura 3: Probabilidade de acerto dos alunos do $8^{\circ}$ ano do ensino fundamental em relação à distribuição da espécie analisada, após terem identificado corretamente a mesma. As barras representam intervalos de confiança (95\%). 


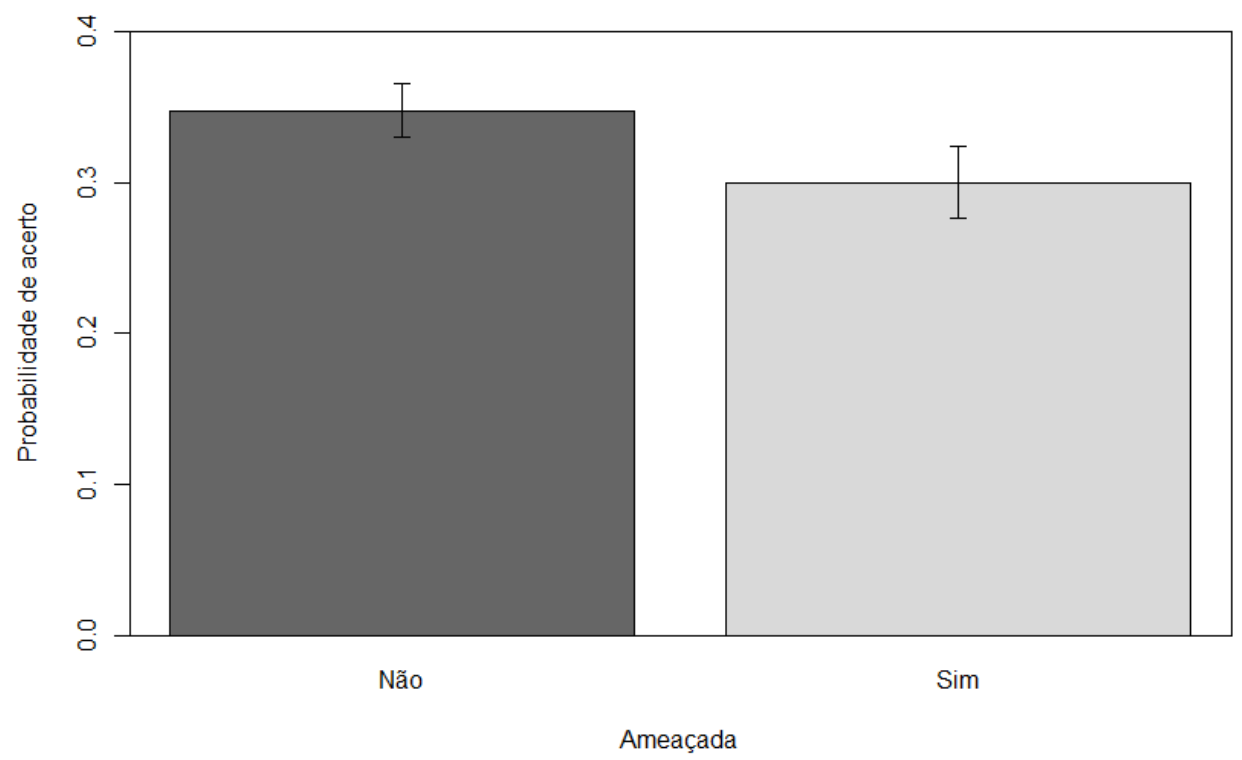

Figura 4: Probabilidade de acerto dos alunos do $8^{\circ}$ ano do ensino fundamental em relação ao nível de ameaça da espécie analisada, após terem identificado corretamente a mesma. As barras representam intervalos de confiança (95\%).

Quanto às questões discursivas, apenas $70 \%$ dos alunos apresentaram definições satisfatórias para o conceito de espécie ameaçada e $64 \%$ para o conceito de espécie extinta. Determinadas respostas referentes ao conceito de extinção sugerem que alguns alunos já refletiram previamente sobre o assunto e demonstram interesse na conservação das espécies. Alguns exemplos foram selecionados e estão apresentados abaixo:

"Significa que se não preservarmos as espécies elas vão deixar de existir. " Masculino - 13 anos

"Que está acabando por poluição ou o ser humano está acabando com a espécie. " Masculino - 14 anos

Após a leitura e categorização das respostas, observou-se que, em relação ao conceito de espécie ameaçada, as respostas puderam ser organizadas em três categorias. A categoria mais comum, representada pela expressão "Que tem poucos indivíduos, que está acabando" foi mencionada por $47 \%$ dos alunos. A segunda categoria mais comum, representada pela expressão "Que corre risco de extinção" foi mencionada por $32 \%$ dos alunos. As demais respostas foram agrupadas na categoria "Outros".

Foi observado também que aproximadamente $10 \%$ dos participantes relacionaram o conceito de espécie ameaçada a ação de caçadores, apresentando, por exemplo, as seguintes definições: "Que está em falta, ou seja, existem poucos no mundo, estão desaparecendo por causa de 
caçadores", "Que está sendo caçada intensamente", "Existem poucos no mundo por causa dos caçadores". Outros casos isolados relacionaram os conceitos de ameaçado e extinto à reprodução: "Uma espécie que praticamente tem poucos, e poucas fêmeas ou machos para cruzar" e "É que não tem fêmea ou macho para se reproduzir". Outros participantes erroneamente trocaram o conceito de espécie extinta com o de espécie exótica, como por exemplo: "Uma espécie que não tem no Brasil".

Durante a aplicação do questionário muitos alunos reportaram o tatubola ( $T$. tricinctus) e o tamanduá-bandeira ( $M$. tridactyla) como animais "de carne gostosa", o que pode refletir práticas familiares comuns e demonstram uma menor preocupação com o impacto da caça nas populações silvestres. Um exemplo observado nas respostas pode ser encontrado abaixo:

"Significa dizer que a espécie está ameaçada porque o humano querem matar pra comer exemplo, tatu, tamanduá, e outro, ou pra fazer casacos e roupas etc." Masculino - 14 anos

Quanto ao conceito de espécie extinta, percebeu-se que os alunos compreendem mais facilmente esse conteúdo. Foram identificadas apenas duas categorias para esse conceito. A primeira categoria, representada pela expressão "Que não existe mais", representou $87 \%$ das respostas. As demais respostas (13\%), foram incluídas na categoria "Outros". Algumas respostas foram surpreendentes, apresentando inclusive exemplos para espécies extintas, como:

"Que não existe mais, se acabou para sempre... Ex.: Dente de sabre (um tigre do gelo), Dodô... (uma ave antiga) " Feminino - 12 anos

\section{Discussão}

O questionário aplicado demostrou que a maior parte das identificações corretas foram para as espécies exóticas, sugerindo prevalecer a prática do ensino com exemplos de espécies pertencentes a outros biomas. O grande número de espécies exóticas inseridas nos livros didáticos e divulgadas na mídia, por serem populares fontes de informação, fazem com que a população tenha um maior interesse por organismos de outras regiões e deixe de conhecer a biodiversidade local. Esse processo contribui para a formação de um conceito distorcido de meio ambiente e das relações ecológicas que ocorrem no local onde a população está inserida (GIORDAN et al., 1996; BIZERRIL et al., 2007). Uma entrevista realizada por Pereira et al. (2006), que buscou analisar as concepções sobre a fauna local e a forma como esse 
conhecimento é transmitido para estudantes indígenas, observou que, mesmo tendo um contato maior com a natureza e com a fauna nativa, os estudantes citaram vários exemplos de animais exóticos, como a zebra, a girafa, o tigre, o elefante, o leão e o urso. Segundo os autores, o resultado foi influenciado pela mídia e pelos materiais escolares, visto que os exemplos da fauna exótica são frequentemente abordados em livros, seja através de exemplos ou de imagens.

Similarmente, Furtado e Branco (2003) também afirmaram, através de uma pesquisa em zoológicos catarinenses que cerca de $35 \%$ dos entrevistados, quando solicitados a citar três animais da fauna nativa, não souberam indicar nenhuma espécie. Os autores sugeriram que a influência da fauna exótica ocorre devido à escassez de documentários sobre a fauna nativa do Brasil. Borges e Ferreira (2015) em um estudo realizado com alunos do 7은 ano de escolas municipais de Anápolis - GO, utilizaram desenhos realizados pelos próprios alunos sobre a biodiversidade do Cerrado. Os autores observaram a citação de animais de outros biomas como sendo nativos, como por exemplo, o leão e a zebra. Ainda de acordo com os autores, mesmo que alguns exemplares da fauna do Cerrado tenham sido desenhados, não está claro para o aluno o meio em que está inserido.

Uma pesquisa realizada com alunos do ensino médio no município de Bauru - SP sobre a caracterização do Cerrado, revelou que as espécies da fauna nativa mais citadas pelos alunos foram genéricas como saguis, cobras e aves (PALHACl et al., 2009). Os autores ainda relataram que os alunos apontaram que zebras e leões também faziam parte da fauna do Cerrado. Resultados semelhantes foram encontrados no trabalho de Bezerra et al. (2013), onde os alunos foram solicitados a exemplificar espécies nativas do Cerrado, sendo o tatu-bola e a capivara as espécies mais citadas. Apesar disso, os alunos também citaram espécies animais que não pertencem ao bioma Cerrado nas respostas, como a girafa, o leão e o urso. O questionário aplicado pelo presente trabalho apresentou resultados semelhantes, onde os animais da fauna nativa como a capivara ( $H$. hydrochaeris), o tamanduábandeira ( $M$. tridactyla) e o tatu-bola ( $T$. tricinctus) foram bem reconhecidos, porém, em muitos casos, os animais como a seriema (C. cristata), lobo-guará (C. brachyurus) e o veado-mateiro (Mazama americana), foram classificados como exóticos. Da mesma forma, espécies exóticas como leão $(P$. leo) e o elefante ( $L$. africana) foram classificadas como pertencentes ao bioma Cerrado.

Animais como sagui (Callithrix penicillata) e macaco-prego (Sapajus libidinosus) foram muito pouco conhecidos pelos participantes, diferente de espécies exóticas como hipopótamo (Hippopotamus amphibius) e javali ( $P$. africanus). Um estudo realizado com alunos do ensino médio em uma escola pública do Triangulo Mineiro, com intuito de investigar o conhecimento dos alunos sobre a fauna do Cerrado através de entrevistas, apontou resultados semelhantes, onde animais como seriema e veado foram pouco conhecidos, ao contrário de alguns exemplares da fauna exótica, como leões e elefantes (RODRIGUES et al., 2001). 
Os resultados do questionário aplicado aos alunos do $8^{\circ}$ ano do ensino fundamental sugerem que o conteúdo sobre a fauna nativa provavelmente não está sendo trabalhado de forma adequada em sala de aula. Diniz (2009), em entrevista realizada com professores de escolas públicas de ensino fundamental revelou, ao questionar professores sobre a importância de se abordar a fauna nativa na escola, que as respostas apresentavam um padrão, ressaltando a importância da preservação e conservação de espécies. Porém, ao serem questionados sobre qual seria o conceito de espécie nativa, a maioria não respondeu ou respondeu de maneira abstrata, como por exemplo: "São animais da fauna nativa". A compreensão correta dos conceitos ecológicos por docentes é essencial para colocar em prática a interdisciplinaridade da área (MOREIRA et al., 2007).

Um questionário aplicado aos alunos de $5^{\circ}$ e $6^{\circ}$ ano sobre a diferença entre animais nativos e exóticos e a forma que o contato com a fauna acontece, apontou que $62 \%$ afirmaram saber a diferença entre nativo e exótico, porém, ao serem questionados, poucos souberam de fato conceituar. O mesmo estudo mostrou que, além de não saberem o conceito de nativo e exótico, eles também desconhecem o conceito de extinção, visto que foi confundido com o conceito de animal exótico (DINIZ, 2009).

Os resultados do presente estudo revelaram que o conhecimento dos alunos sobre o conceito de espécie ameaçada apresentou definição satisfatória por $70 \%$ dos participantes. Um estudo realizado em Chapecó - SC, acerca das concepções dos estudantes sobre espécies ameaçadas, revelou que $96 \%$ dos estudantes relataram já terem ouvido falar em espécies ameaçadas de extinção. Destes, $56 \%$ demonstraram compreensão sobre o assunto e $44 \%$, apesar de já terem ouvido falar em espécies ameaçadas de extinção, não souberam formular uma resposta compreensível ou responderam de forma equivocada sobre o que entendiam por extinção. Isso pode estar relacionado a dificuldades na escrita, de expressão ou de organização de ideias e ter sua origem na falta de leitura. A maioria dos estudantes (80\%) não citou espécies ameaçadas de extinção ocorrentes na região, o que representa a falta de conhecimento sobre as espécies e sua ocorrência (CAVASOTTO; VALDAMERI, 2010).

Um estudo realizado com alunos do ensino médio no estado do Ceará sobre animais ameaçados de extinção mostrou que, ao questionarem os alunos sobre o que seria extinção de espécies, 95\% dos alunos souberam responder de forma correta. Além disso, quando questionados se o seu conhecimento sobre a extinção de espécies era considerado satisfatório, 55\% afirmaram que sim. Ao serem questionados se o tema era abordado em sala de aula, $59 \%$ afirmaram que sim e $96 \%$ disseram que o tema deveria ser mais abordado dentro de sala de aula. Verificou-se que a maioria dos alunos apresenta conhecimento prévio e familiaridade com o assunto. Dessa forma, pode-se observar que o conteúdo vem sendo trabalhado em sala de aula, o que é essencial para a sensibilização e, consequentemente, proteção das espécies (LIMA, 2014).

Revbea, São Paulo, V. 13, № 4: 260-280, 2018. 
No presente estudo, algumas respostas referentes ao conceito de espécie extinta demonstraram que os participantes possuem algum nível de consciência ambiental e interesse na conservação das espécies. Esse resultado também foi observado em um estudo sobre as concepções de alunos do ensino médio sobre biodiversidade. $O$ estudo demonstrou que, de forma geral, os alunos apresentam consciência ecológica, visto que $91,3 \%$ concordam que os seres humanos são responsáveis de alguma forma pela extinção das espécies. Porém, as respostas indicaram que os alunos apresentavam conhecimentos pouco elaborados sobre as causas e consequências e no estabelecimento da relação entre os animais e a extinção (DINIZ et al., 2005). Alguns alunos, assim como no estudo de Diniz e colaboradores (2005), conceituaram extinção de forma pouco elaborada e confusa, alguns mesclaram os conceitos de espécies ameaçadas e extinta e outros relacionaram com fatores reprodutivos.

O conhecimento sobre a biodiversidade é uma importante ferramenta para a conservação das espécies, algumas já ameaçadas. Pois é através desse conhecimento que o indivíduo desperta e é estimulado a um envolvimento mais consciente e responsável com relação ao meio ambiente (PÁDUA et al., 2003). O conhecimento do aluno sobre a fauna está ligado ao interesse e à importância que a fauna representa para ele (DREWS, 2002).

Algumas estratégias para estimular o conhecimento e sensibilizar os alunos quanto à importância da proteção da fauna nativa precisam e devem ser adotadas, como por exemplo, a utilização de cartilhas, livros didáticos e paradidáticos voltados para a disseminação de informações sobre a fauna nativa; a discussão sobre listas de espécies ameaçadas; o uso de documentários e atividades de campo onde espécies nativas possam ser identificadas, dentre outros. Alguns estudos comparam os efeitos da adoção de algumas dessas estratégias no conhecimento dos alunos em relação à fauna local. Um estudo realizado com alunos do $1^{\circ}$ ano do ensino médio de uma escola pública do Distrito Federal avaliou o conhecimento dos alunos sobre o bioma Cerrado e sua fauna nativa antes e depois de uma atividade de campo. Os resultados demonstraram que antes da saída de campo os alunos conseguiram citar pelo menos uma espécie nativa e que após a saída de campo houve maior diversidade nas respostas (MEIRELES et al., 2012). Similarmente, Diniz (2009), ao avaliar o conhecimento de alunos sobre a fauna nativa antes e depois de apresentar uma cartilha ilustrada com imagens de animais do Cerrado, percebeu que houve um aumento no número de citações de animais nativos após a apresentação do material.

\section{Considerações finais}

Os resultados demonstraram que algumas mudanças são necessárias na forma como o conteúdo é trabalhado em sala de aula e também revelaram que alguns conceitos apresentados pelos alunos são preocupantes para o sucesso de ações relacionadas à conservação das espécies.

revista brasileira educação ambiental 
Poucos trabalhos buscaram investigar o conhecimento da população sobre a biodiversidade do Cerrado, porém, acredita-se que muitas espécies características são desconhecidas por grande parte da população. O despertar para a conservação das espécies está intimamente relacionado ao conhecimento popular das mesmas. Se o sujeito possui uma identificação ecológica, é possível promover uma condição favorável para ações de educação ambiental. Os livros didáticos, documentários, atividades fora de sala de aula, dentre outros meios de comunicação, podem atuar estimulando a busca pelo conhecimento sobre a fauna nativa e a sua conservação, além de estimular a participação ativa, favorecem a tomadas de decisões e, portanto, a mudança de atitudes, pois a formação do pensamento crítico somente ocorrerá se houver efetiva sensibilização.

\section{Agradecimentos}

Agradecemos às Regionais de Ensino do Distrito Federal e aos diretores e professores das escolas por permitirem a execução do presente estudo. Agradecemos também à Andrea Libano e ao Fabrício Escarlate pelos comentários e sugestões na versão preliminar desse manuscrito.

\section{Referências}

AGUIAR, L. M. S.; MACHADO, R. B.; MARINHO-FILHO, J. A diversidade biológica do Cerrado. In: AGUIAR, L. M. S; CAMARGO, A. J. A., eds. Cerrado: ecologia e caracterização Embrapa Cerrados, Planaltina, p.17-40, 2004.

ALHO, C. J. R., MARTINS, E. S. De Grão em Grão o Cerrado Perde Espaço (Cerrado - Impactos do Processo de Ocupação). WWF - Fundo Mundial para a Natureza. Brasília, p. 66, 1995.

BARBOSA, M. O.; ALMEIDA, M. L. Novas observações e dados reprodutivos do pato-mergulhão Mergus octosetaceous na região do Jalapão, Tocantins, Brasil. Cotinga: v. 32, p. 109-113, 2010.

BEZERRA, R. G.; SUESS, R. C. Abordagem do bioma Cerrado em livros didáticos de Biologia do Ensino Médio. Holos, Natal, v. 1, n. 29, p. 233-242, 2013.

BIZERRIL, M. X. A. O cerrado nos livros didáticos de geografia e ciências. Ciência Hoje, Rio de Janeiro, v. 32, n.192, p. 56-60, 2003.

BIZERRIL, M. X. A. Children's Perceptions of Brazilian Cerrado Landscapes and Biodiversity. The Journal of Environmental Education, v. 35, p. 47-58, 2004.

BIZERRIL, M. X. A.; LOUZADA, D.; ROCHA, D. M. S.; PERES, J.; FURONI, G. Percepção de alunos de ensino fundamental sobre a biodiversidade: relações entre nomes de organismos, mídia e periculosidade. In: VI ENPEC - Encontro Nacional de Pesquisa em Educação em Ciências, 2007, Florianópolis. Anais... Belo Horizonte: ABRAPEC, 2007, p. 319.

Revbea, São Paulo, V. 13, № 4: 260-280, 2018. 
BORGES, P. S.; FERREIRA, J. S. A percepção ambiental de alunos sobre o bioma Cerrado por meio da utilização de desenhos. In: VI EDIPE Encontro Estadual de Didática e Práticas de Ensino, 2015, Goiânia. Anais... Anápolis: CEPED UEG, 2015. v. 1. p. 1-19.

BRASIL. Ministério da Educação e Cultura, Parâmetros Curriculares Nacionais - Meio Ambiente e Saúde. 1998a. Disponível em: http://portal.mec.gov.br/seb/arquivos/pdf/livro01.pdf. Acesso em: 14 mar. 2016.

BRASIL. Lei no 9.605, de 12 de fevereiro de 1998b. Dispõe sobre as sanções penais e administrativas derivadas de condutas e atividades lesivas ao meio ambiente, e dá outras providências. Disponível em: http://www.planalto.gov.br/ccivil 03/leis/L9605.htm. Acesso em: 17 nov. 2016.

MMA. 0 Bioma Cerrado. Disponível em: http://www.mma.gov.br/biomas/cerrado. Acesso em: 23/02/2016.

BRASIL. Ministério do Meio Ambiente, Programa Nacional de Conservação e Uso Sustentavel do Bioma Cerrado - Programa Cerrado Sustentável. Brasília, p. 56, 2006.

BRAZ, V. S.; ABREU, T. L. S.; LOPES, L. E.; LEITE, L. O.; FRANÇA, F. G. R. VASCONCELLOS, M. M.; BALBINO, S. F. Brazilian Merganser Mergus octosetaceus discovered in Jalapão State Park, Tocantins, Brazil. Cotinga v. 20, p. 68-71, 2003.

CANDIA-GALLARDO, C. E.; SILVEIRA, L. F.; KUNIY, A. A. A new population of the Cone-billed Tanager Conothraupis mesoleuca, with information on the biology, behaviour and type locality of the species. Bird Conservation International v. 20 p. 149-160, 2010.

CAPRA, F. et al. Alfabetização ecológica: a educação das crianças para um mundo sustentável. São Paulo: Cultrix, 2008.

CAVASOTTO, E. I.; VALDAMERI, R. As espécies ameaçadas de extinção e o ensino de ciências. 2010. 50 f. Monografia (graduação) - Universidade Comunitária Regional de Chapecó.

COIMBRA, A. O tratamento da Educação Ambiental nas conferências ambientais e a questão da transversalidade. Revista eletrônica do Mestrado de Educação Ambiental. Rio Grande, RS, v. 16, p. 131-142, 2006.

COLLI, G. R.; BASTOS, R. P.; ARAÚJO, A. F. B. The character and dynamics of the Cerrado Herpetofauna. In: OLIVEIRA, P.S.; MARQUIS, R.J. (Eds.) The Cerrados of Brazil: Ecology and the Natural History of a Neotropical Savanna. New York: Columbia University Press, p. 223-241, 2002.

COSTA, T. B.; SANTOS, M. P.; LARANJEIRAS, D. O.; GUIMARÃES, L. D. A visão do bioma Cerrado no Ensino Fundamental do município de Goiânia e sua relação com os livros didáticos utilizados como instrumento de ensino. Polyphonía, v. 21, n. 1, jan./jun., 2010. 
CRUZ, G. A. C., PIMENTA, B. Phrynomedusa fimbriata. The IUCN Red List of Threatened Species 2004: e.T17078A6797217. http://dx.doi.org/10.2305/IUCN.UK.2004.RLTS.T17078A6797217.en, 2004.

CUTTER-MACKENZIE, A., SMITH, R. Ecological literacy: the 'missing paradigm' in environmental education (part one). Environmental Education Research v. 9, p. 497-524, 2003.

DIAS, B. F. S. Cerrados: Uma caracterização. In: DIAS B. F. F., ed. Alternativas de Desenvolvimento dos Cerrados: Manejo e Conservação dos Recursos Naturais Renováveis. Brasília: Fundação Pró-Natureza, p. 11-25, 1992a.

DIAS, G. F. Educação ambiental: princípios e práticas. São Paulo: Gaia. p. 399, 1992b.

DINIZ, E. M.; TOMAZELLO, M. G. C. Crenças e concepções de alunos do ensino médio sobre biodiversidade: um estudo de caso. In: $\mathrm{V}$ ENCONTRO NACIONAL DE PESQUISA EM EDUCAÇÃO EM CIÊNCIAS. Atas..., 5. 2005.

DINIZ, M. F. Cartilha ilustrada com alguns animais nativos do cerrado: um material paradidático de ciências, para estudantes de escolas públicas de Esmeraldas - MG. Dissertação de Mestrado. Pontifícia Universidade Católica de Minas Gerais, Belo Horizonte, 2009.

DREWS, C. Attitudes, knowledge and wild animals as pets in Costa Rica. Anthrozoös, v. 15 n. 2, p. 119-138, 2002.

FELFILI, J.M.; SOUSA-SILVA, J.C.; SCARIOT, A. Biodiversidade, ecologia e conservação do Cerrado: avanços do conhecimento. In: SCARIOT, A.; SOUSASILVA, J.C.; FELFILI, J.M. (Org.). Cerrado: ecologia, biodiversidade e conservação. Brasília: Ministério do Meio Ambiente, p.25-44, 2005.

FREITAS, Y. E.; FERRAZ, K. D. I. A floresta amazônica do ponto de vista dos alunos da $5^{\underline{a}}$ série da rede pública estadual de Manaus, Amazonas, Brasil. Acta Amazônica, v. 29, n. 4, p. 535-540, 1999.

FURTADO, M. H. B. C; BRANCO, J. O. A percepção dos visitantes dos zoológicos de Santa Catarina sobre a temática ambiental. In: II SIMPÓSIO SUL BRASILEIRO DE EDUCAÇÃO AMBIENTAL. Anais..., 2003, UNIVALI, Santa Catarina.

GIORDAN, A.; VECCHI, G. As origens do saber: das concepções dos aprendentes aos conceitos científicos. 2. ed. Porto Alegre: Artes Médicas, 1996.

GONÇALVES, C. W. P. Os (des)caminhos do meio ambiente. 10. ed. São Paulo: Contexto, (Temas Atuais). 2002.

GOSETH, M. O. Os animais e o homem. O correio da Unesco, v. 16, 1988.

IUCN. The Red List of Threatened Species. Version 2017-1. Disponível em: www.iucnredlist.org. Acesso em: 05 Mar. 2017. 
JACOBI, P. R. Educação ambiental: o desafio da construção de um pensamento crítico, complexo e reflexivo. Educação e Pesquisa, São Paulo, v. 31, n. 2, p. 233-250, Aug. 2005.

KLINK, C. A.; MACHADO, R. B. Conservation of the Brazilian Cerrado. Conservation Biology, v. 19, p. 707-713, 2005.

KLINK, C. A.; MOREIRA, A.G. Past and current human occupation, and land use. In: OLIVEIRA, M.S.; MARQUIS, R.J. (Ed.) The Cerrados of Brazil: Ecology and natural history of Neotropical savanna. New York: Columbia University Press, 2002. cap.5, p. 69-90.

LIMA, B. S. S. O conhecimento dos alunos do ensino médio do CEJA de Iguatu, Ceará, sobre animais ameaçados de extinção no estado. 2014, $51 \mathrm{f}$. Monografia (graduação). Universidade Estadual do Ceará.

MACEDO, R. H. F. The Avifauna: Ecology, Biogeography, and Behavior. In: OLIVEIRA, P. S.; MARQUIS, R. J. (Org.) The Cerrados of Brazil: Ecology and natural history of a neotropical savanna. New York: Columbia University Press, p. 398, 2002.

MACHADO, L. M. C. P. A percepção do meio ambiente como suporte para a educação ambiental. In: POMPÊO, M. L.M. (ed.) Perspectivas na Limnologia no Brasil. União, 1999. p. 1- 13.

MACHADO, R.B.; RAMOS NETO, M.B.; PEREIRA, P.G.P.; CALDAS, E.F.; GONÇALVES, D.A.; SANTOS, N.S.; TABOR, K.; STEININGER, M. Estimativas de perda da área do Cerrado brasileiro. Relatório técnico não publicado. Conservação Internacional. Brasília/DF: MCT, 2004.

MARINHO-FILHO, J., RODRIGUES, F.H.G.; JUAREZ, K.M. In: P.S. OLIVEIRA \& R.J. MARQUIS, Org. The Cerrados of Brazil: Ecology and natural history of a Neotropical Savanna. The Cerrado Mammals: Diversity, Ecology, and Natural history. New York . Ed. Columbia University Press, p. 266-284, 2002.

MEIRELES, G. C.; HALL, C. F. O despertar de valores ecológicos nas escolas: conhecer e preservar o cerrado por meio da pesquisa de campo. Enciclopédia biosfera, Centro Científico Conhecer, Goiânia, v.8, n.15; p. 2154, 2012.

MIRANDA, F. M. C. S. M. Conhecimentos faunísticos dos alunos de ensino básico: implicações educacionais, ambientais e conservacionistas. Faculdade de Ciências da Universidade do Porto. 2007.

MORAES, E. M. M.; SILVA, I. R. Educação e Meio Ambiente na percepção de alunos de escolas públicas do bairro do coroado - Manaus/Am. Relatório Final de PIBIC pela Universidade Federal do Amazonas, 2006.

MOREIRA, A. L. O. R. et al. Biodiversidade na realidade escolar - investigação da prática docente no ensino. In: Anais do VI Encontro Nacional de Pesquisa em Educação em Ciências, 2007, Santa Catarina. Disponível em: http://www.fae.ufmg.br/abrapec/viempec/viempec/CR2/p996.pdf. Acesso em: 08/06/2016. 
MYERS, N.; MITTERMEIER R. A.; MITTERMEIER C. G.; FONSECA G.A.B; KENT, J. Biodiversity hotsposts for conservation piorities. Nature, London v. 403, p. 853-858, 2000.

OLIVEIRA, S. K. S. Percepção da Educação Ambiental e Meio Ambiente no Ensino Fundamental: Olhares em Porto do Mangue/RN. Dissertação (Desenvolvimento e Meio Ambiente). UERN. Mossoró-RN. 119. 200

PÁDUA, S.M.; TABANEZ, M.F.; SOUZA, M.G. A abordagem participativa na educação para a conservação da natureza. In: CULLEN, JR., L. RUDRAN, R.; VALLADARES PÁDUA, C. (Org.). Métodos de estudos em biologia da conservação e manejo da vida silvestre. Curitiba: Universidade Federal do Paraná; Fundação O Boticário de Proteção à Natureza, 2003. p. 557-591.

PALHACI, T. P.; BRANDO, F. R.; PLALHACI, M. C. J. P.; CALDEIRA, A. M. A. Caracterização do bioma Cerrado por alunos do Ensino Médio. In: ENCONTRO NACIONAL DE PESQUISA EM EDUCAÇÃO EM CIÊNCIAS, 7., 2009, Florianópolis. Anais... Florianópolis, ABRAPEC, 2009.

PEDERSOLI, F. T. Etnozoologia como ferramenta para o Ensino de Biologia: unindo os saberes para a aprendizagem. Educação e Biodiversidade, 2008.

PEREIRA, R. P. J.; BOCCARDO, L.; RAZERA, C. C. J. Percepções sobre a fauna em estudantes indígenas de uma tribo tupinambá: um caso de etnozoologia. 2006.

PINHEIRO DA SILVA, P. G.; CAVASSAN, O. A influência da imagem estrangeira para o estudo da botânica no ensino fundamental. In: ENCONTRO DE PESQUISA EM EDUCAÇÃO EM CIÊNCIAS, Bauru. Atas..., p. 1-4., 2003

PRIMACK, R. B.; RODRIGUES, E. Biologia da Conservação. Londrina: Midiograf, p. 327, 2001.

REIGADA, C., REIS, M. F. C. T. Educação Ambiental para crianças no ambiente urbano: uma proposta de pesquisa-ação. Ciência \& Educação, v.10, n.2, p.149-159, 2004.

$R$ CORE TEAM. R: A language and environment for statistical computing. R Foundation for Statistical Computing, Vienna, Austria. URL https://www.Rproject.org/. 2016.

RIBEIRO, J. F.; WALTER, B. M. T. As principais fitofisionomias do bioma Cerrado. In: SANO S. M.; ALMEIDA, S. P. (Orgs.). Cerrado: ambiente e flora. Planaltina, DF, EMBRAPA-CPAC, 2008.

RODRIGUES, C. S. M., CUNHA, O. M. A., GUIDO, E. F. L. Fauna e Flora do Cerrado: Conhecimento dos alunos do Ensino Médio de uma escola pública do Triangulo Mineiro. Universidade Federal de Uberlândia, 2001.

SAUVÉ, L. Environmental Education and Sustainable Development: A Further Appraisal. Canadian Journal of Environmental Education, v. 1, p. 7-34, Mar. 1996.

Revbea, São Paulo, V. 13, № 4: 260-280, 2018. 
Idade:

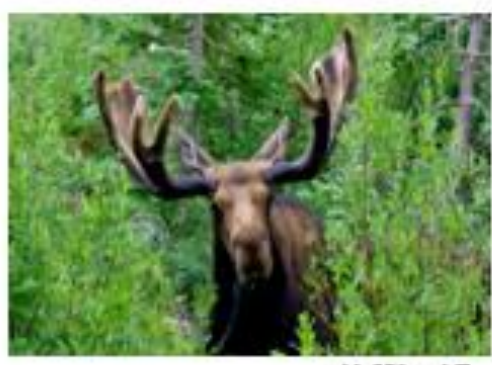

Al Hikes $A Z$

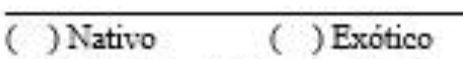

Ameaçado: ( ) $\operatorname{Sim}($ ) Näo

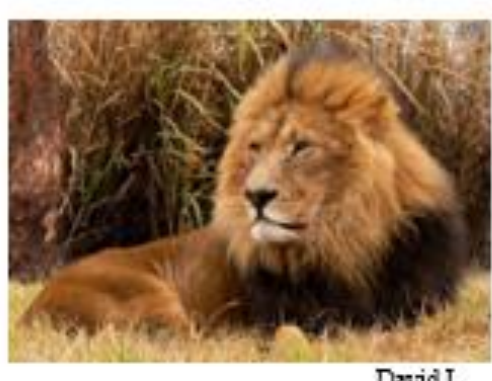

David L.

( ) Nativo ( ) Exótico
Ameaçado: ( ) Sim ( )Näo

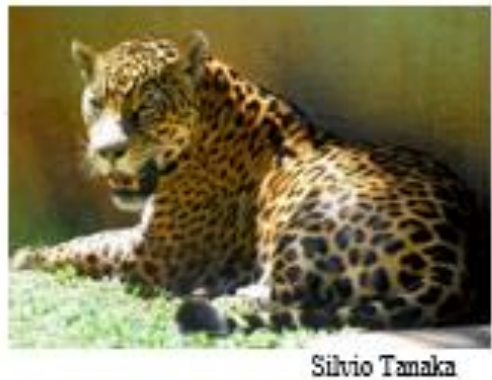

() Nativo ( ) Exótico

Ameaçado: ( ) $\operatorname{Sim}($ ) Näo
Sexo: F( ) M( )
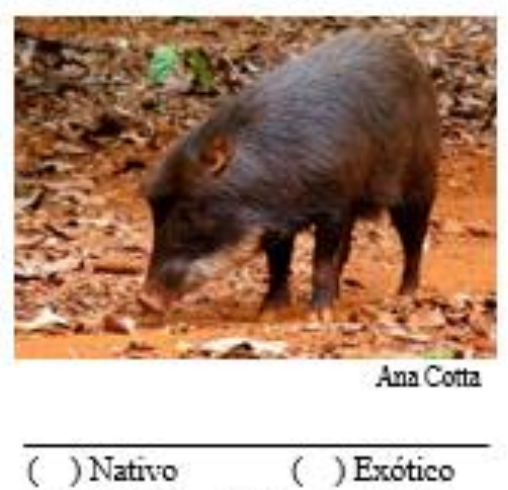

Ameaçado: ( ) Sim ( ) Nào
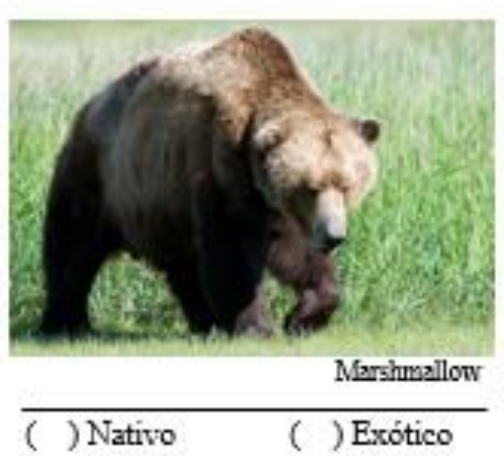

Ameaçado:( ) Sim ( ) Não
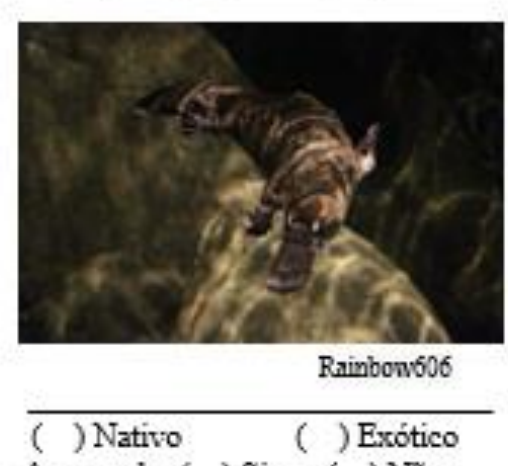

Ameaçado: ( ) Sim ( ) Não
Escola:
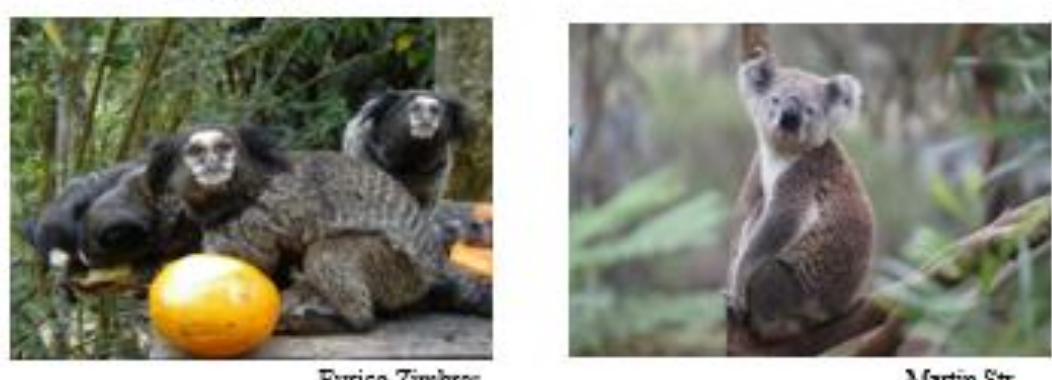

Martin Str

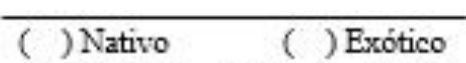

Ameaçado:( ) Sim ( )Näo

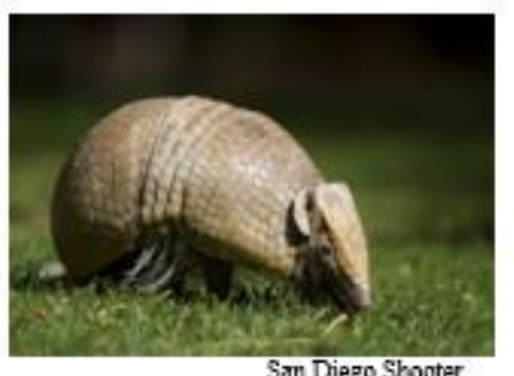

an Diezo Sbooter
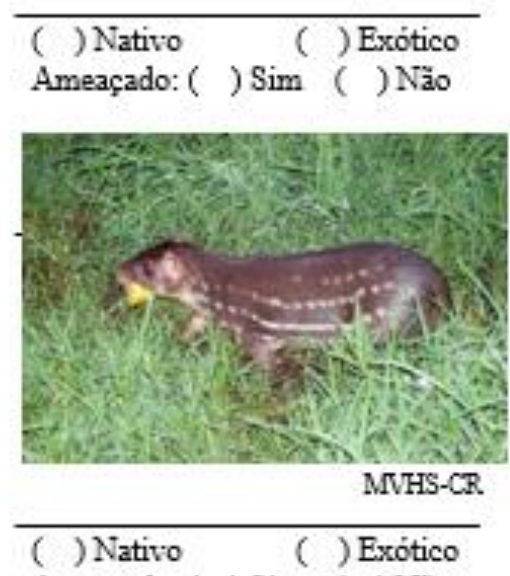

Ameaçado:( ) Sim ( )Näo

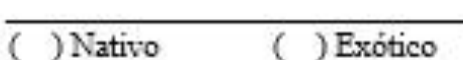

Ameaçado: ( ) Sim ( ) Näo
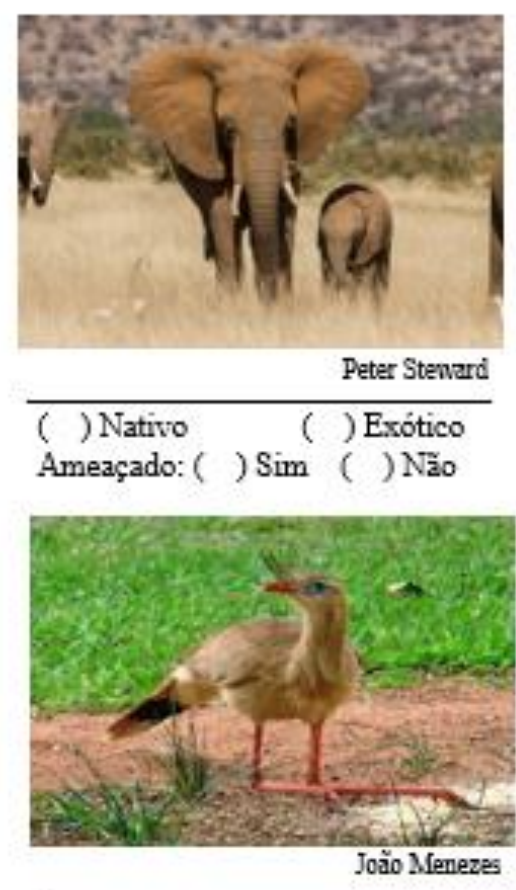

( ) Nativo ( ) Exóticol

Ameaçado:( ) $\operatorname{Sim}$ ( ) Não

Revbea, São Paulo, V. 13, № 4: 260-280, 2018. 


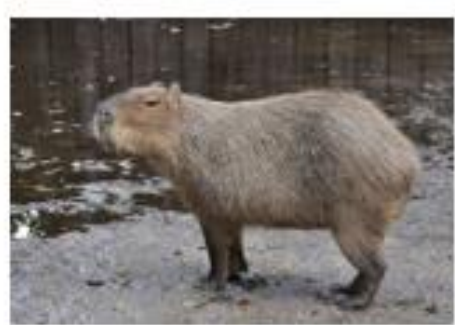

Paul Hermans
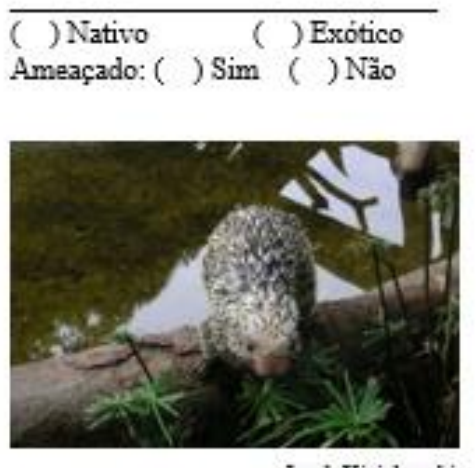

Jacek Kisielewsidi
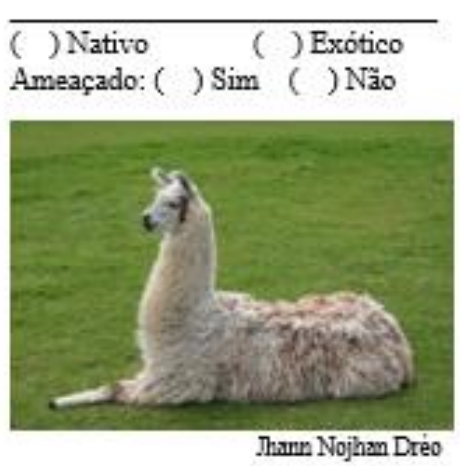

( ) Nativo ( ) Erotico Ameaçado: ( ) Sim ( ) Näo

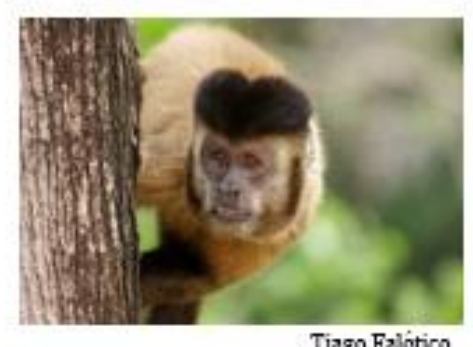

Tiago Felotico
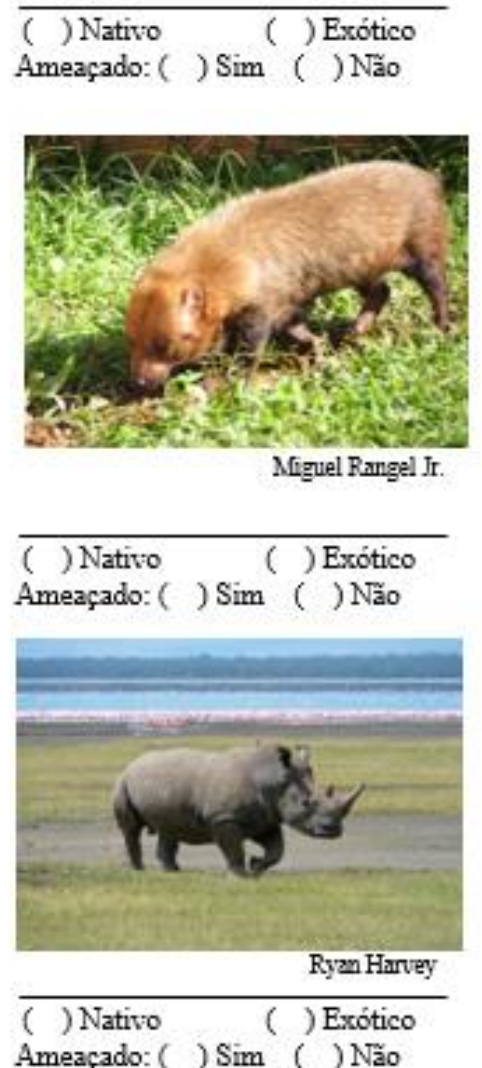

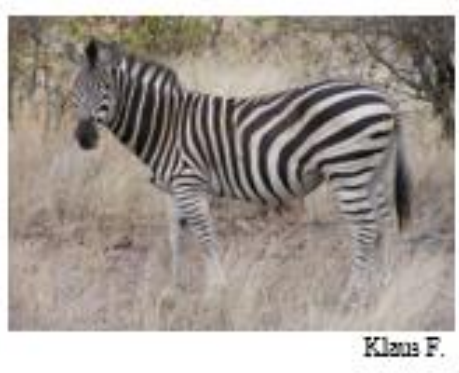

( ) Nativo ( ) Exótico Ameaçado:( ) $\operatorname{Sim}($ ( ) Nào

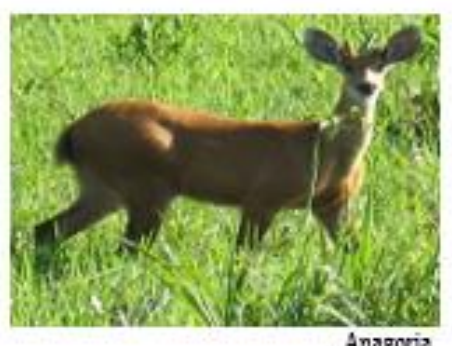

Anagocia
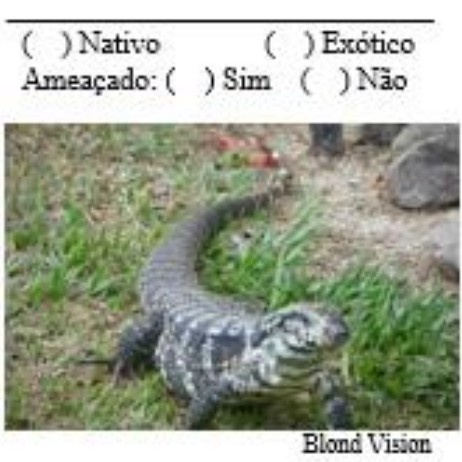

( ) Nativo ( ) Exótico Ameaçado:( ) Sim ( ) Näo
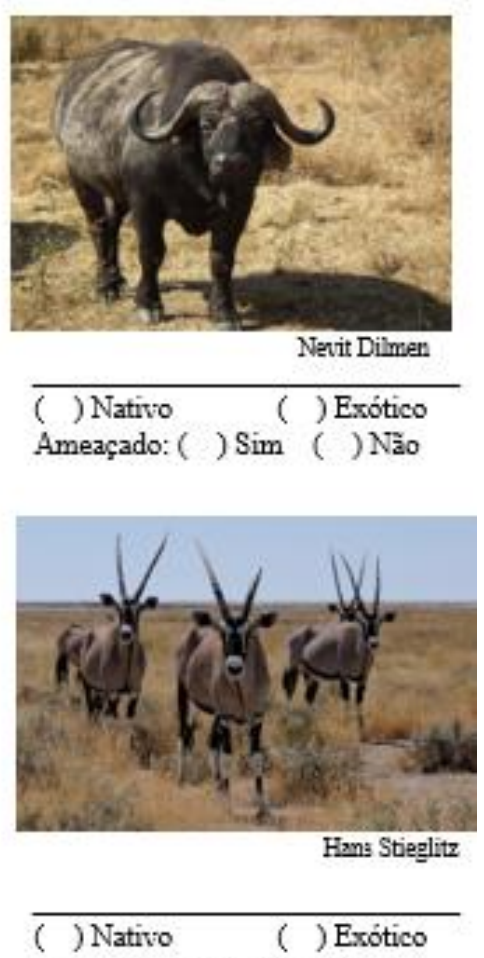

Ameaçado: ( ) $\operatorname{Sim}$ ( ) Não
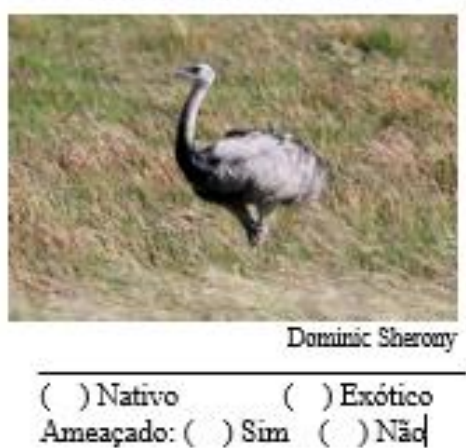

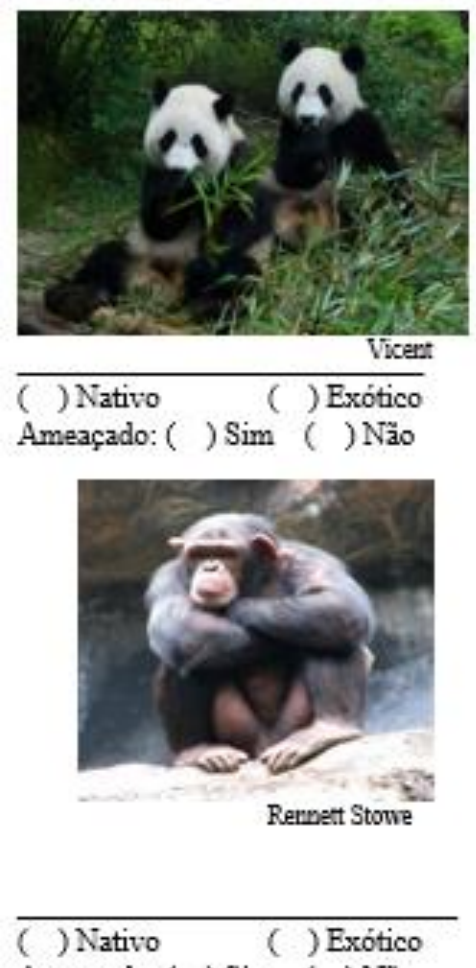

Ameaçado:( ) Sim ( ) Não
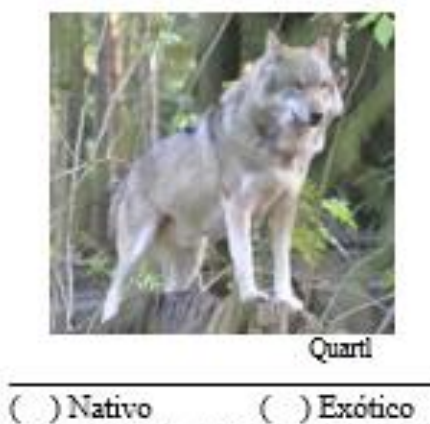

Ameaçado:( ) Sim ( ) Näo
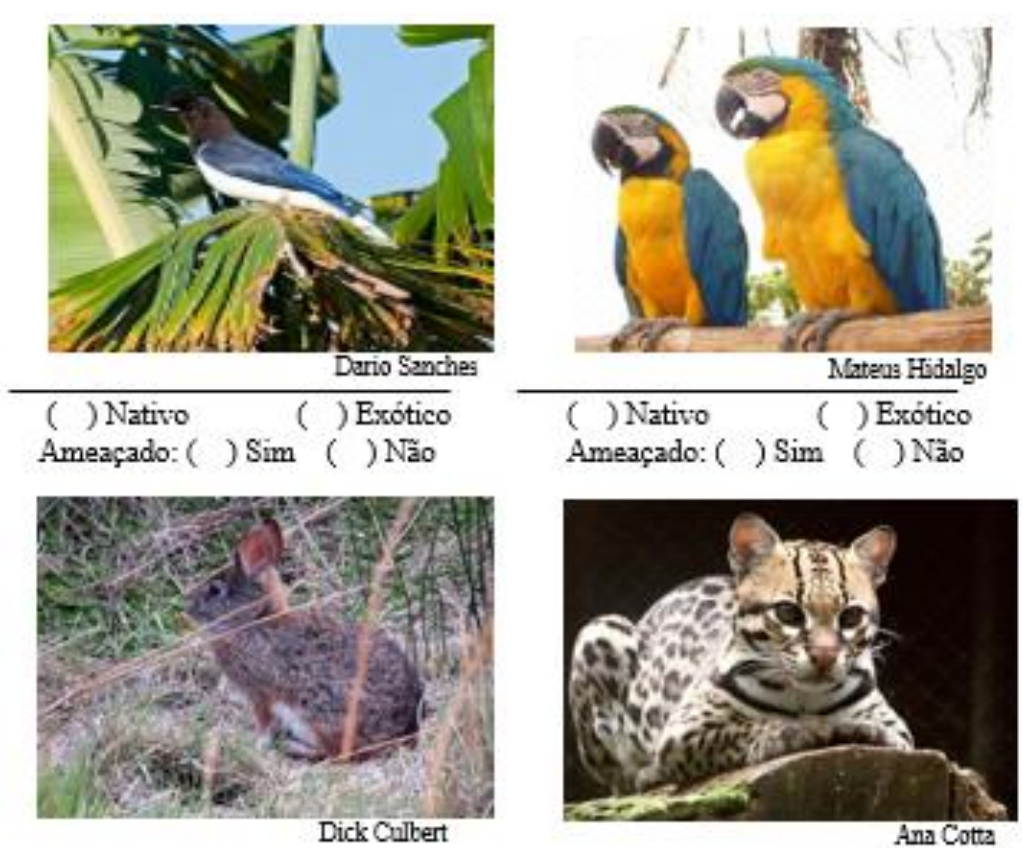

Ana Cotta
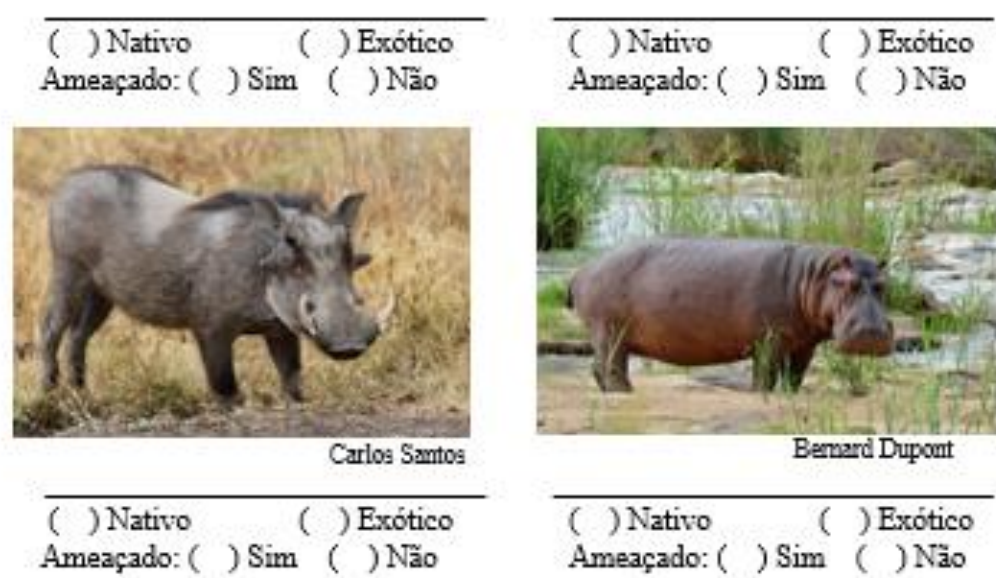
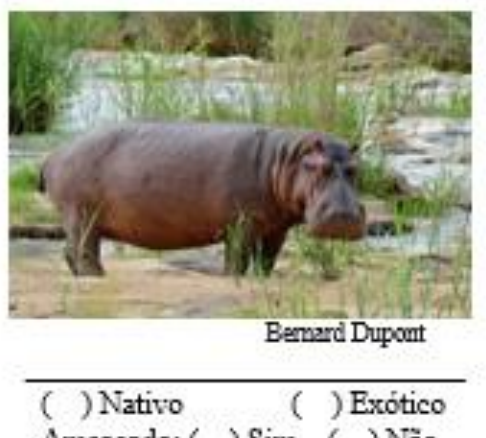
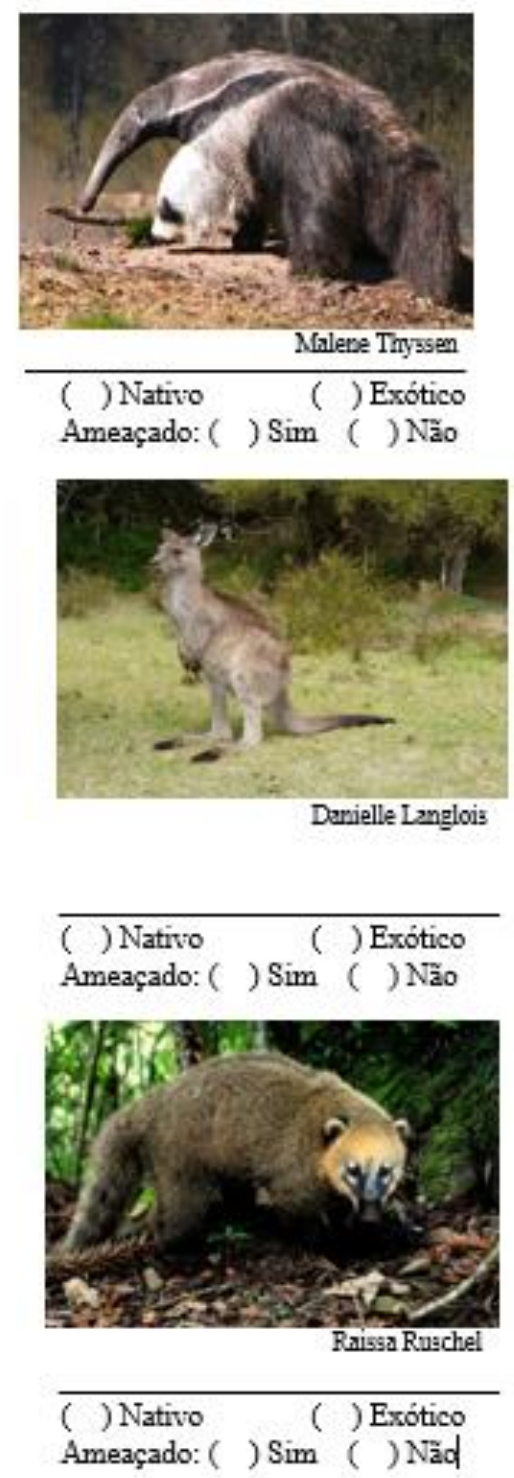

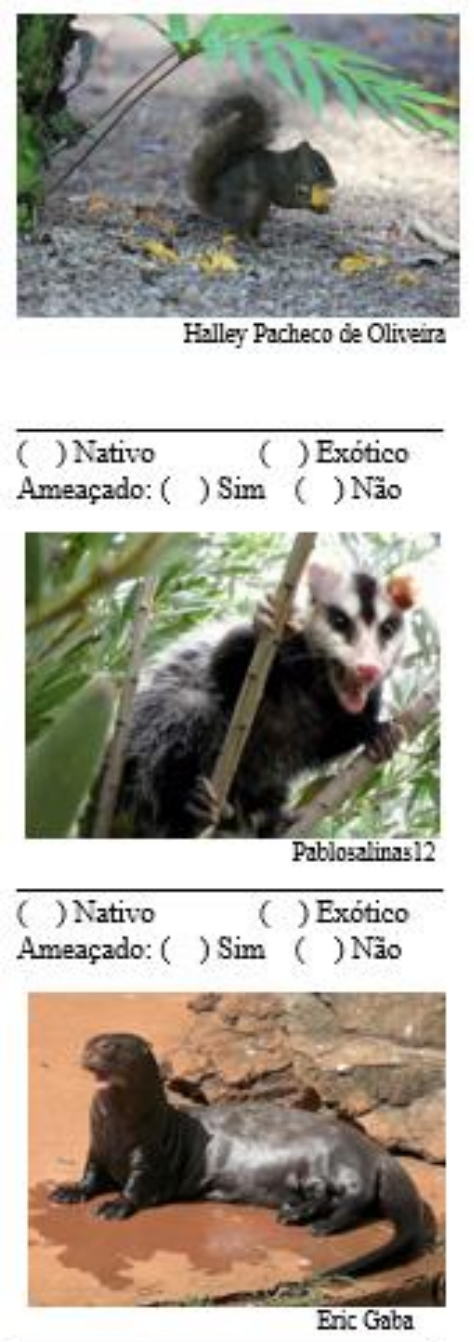

( ) Nativo Exótico Ameaçado:( ) Sim ( ) Näo
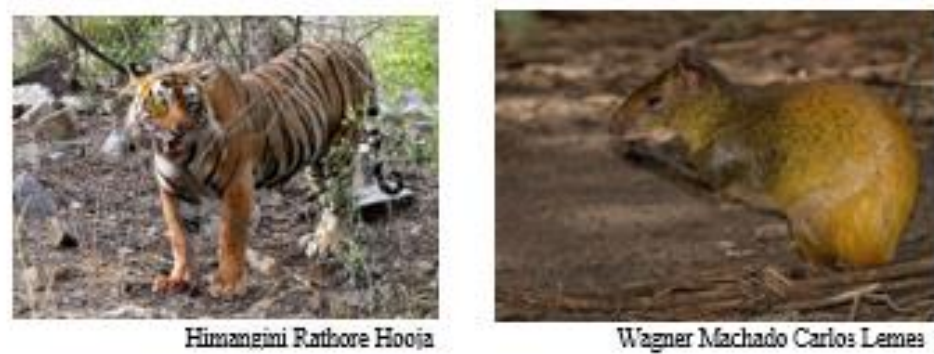

Wagner Machado Carlos Lemes
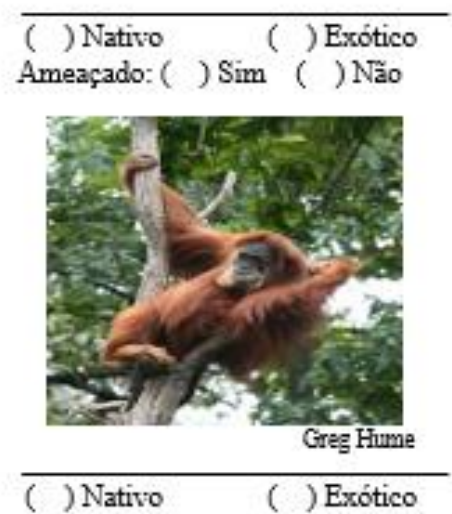

Ameaçado:( ) Sim ( ) Não

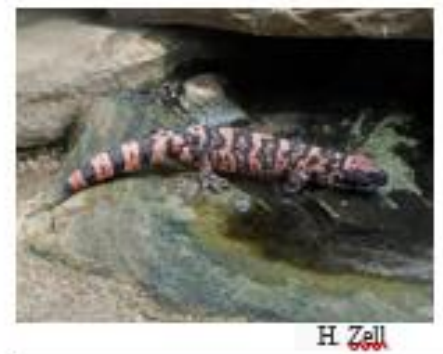

( ) Nativo ( ) Exótico Ameaçado:( ) Sim ( ) Não

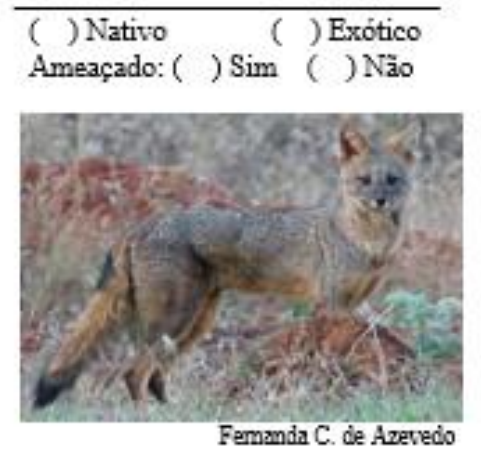

( ) Exótico
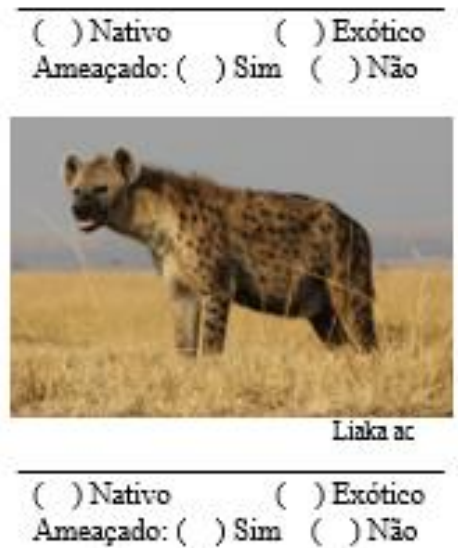
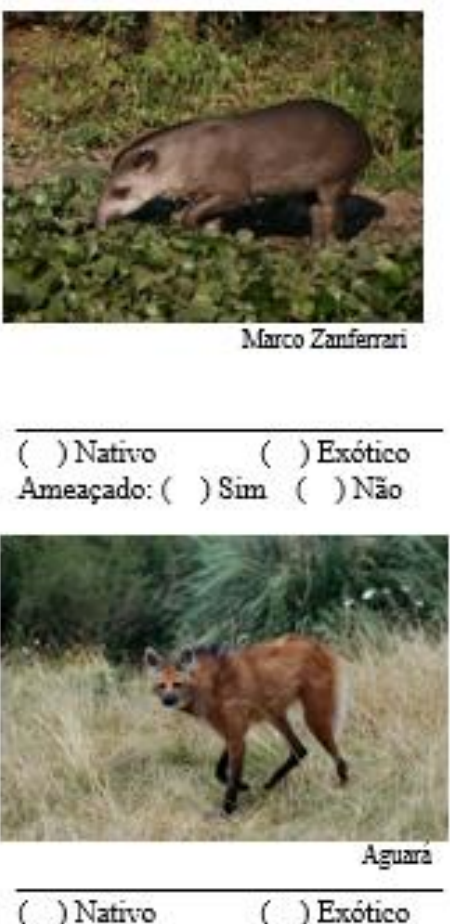

Ameaçado:( ) $\operatorname{Sim}$ ( )Não
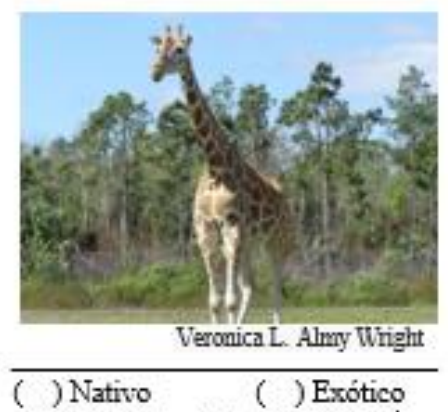
Ameaçado:( ) Sim ( )Nãd 


\section{Anexo I}

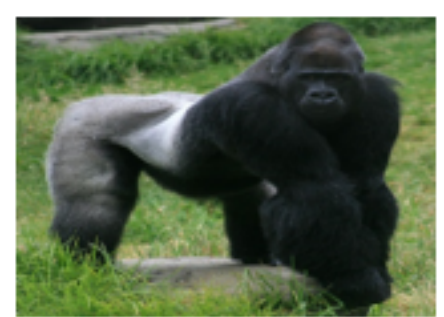

Brocken Insglory

( ) Nativo ( ) Exótico

Ameaçado: ( ) Sim ( ) Näo

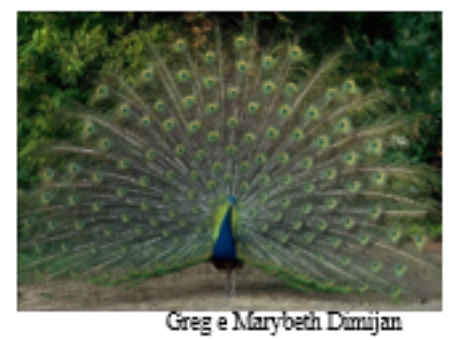

Greg e Narybeh Dimjian

( ) Nativo ( ) Exótico

Ameaçado: ( ) Sim ( ) Nằ

O que significa dizer que uma espécie está ameaçada?

O que significa dizer que uma espécie está extinta? 